\title{
Mapeamento de ravinas e voçorocas nas margens do anel rodoviário da cidade de Vitória da Conquista - BA
}

\section{Mapping of ravines and gullies on the shores of the road ring of the city of Vitória da Conquista - BA}

\section{Mapeo de barrancas y zanjas en las márgenes del cruce de carreteras de la ciudad de Vitória da Conquista - BA}

Lucas Libarino Barbosa ${ }^{1}$ http://orcid.org/0000-0001-8140-2658

Meirilane Rodrigues Maia ${ }^{2}$ http://orcid.org/0000-0001-8757-0601

\footnotetext{
1 Pós-Graduando em Geografia pela Universidade Estadual do Sudoeste da Bahia - UESB -Vitória da Conquista-Bahia-Brasil lucas_kais@hotmail.com

${ }^{2}$ Professora Adjunta do Departamento de Geografia e do Programa de Pós-graduação (PPGEO) da Universidade Estadual do Sudoeste da Bahia - UESB - Vitória da Conquista-Brasil - meire.rmaia@ gmail.com
}

\section{Resumo}

Este artigo analisa as feições erosivas nas margens do anel rodoviário na cidade de Vitória da Conquista BA e mapeia as principais áreas afetadas por ravinas e voçorocas. Para a pesquisa foi realizada revisão bibliográfica sobre o tema e a área de estudos, levantamento de informações cartográficas e coleta de dados em campo. Os processos erosivos foram classificados de acordo com Vieira (1998-2008). Para o geoprocessamento foi utilizado o software Quatum Gis (Qgis) para localização das erosões. O estudo apontou diversas localidades acometidas por feições erosivas com proximidade que chegam até 3 metros da pista. Durante a pesquisa foram identificados onze processos erosivos significativos de caráter linear, todos com menos de vinte metros de distância da pista.

Palavras-chave: Erosão. Ravinas. Voçorocas.

\begin{abstract}
This article analyzes the erosive features on the shores of the road ring, in the city of Vitória da Conquista BA and maps the main areas affected by ravines and gullies. The research was performed literature review on the subject and field of study, survey of cartographic information and data collection in the field. The erosive processes were classified according to Vieira (1998-2008). For the geoprocessing was used the Quatum Gis(Qgis) software for erosion's location. The study pointed out various localities affected by erosive features with closeness that reach up to 3 meters from the runway. During the research were identified eleven erosive processes of significant linear character, all with less than twenty meters of runway.
\end{abstract}

Keywords: Erosion. Ravines. Gullies.

\section{Resumen}

Geopauta, Vitória da Conquista, ISSN: 2594-5033, V. 4, n. 2, 2020, (p. 227-247) http://periodicos2.uesb.br/index.php/geo 
Este artículo analiza las márgenes del cruce de carreteras en la ciudad de Vitória da Conquista - BA y realiza un mapeo de las principales áreas afectadas por barrancas y zanjas. Para dicha investigación se ha hecho una revisión bibliográfica sobre el tema y área de estudios, levantamiento de informaciones cartográficas y recolección de datos de campo. Los procesos erosivos fueron clasificados de acuerdo con Vieira (19982008). Para su geoprocesamiento fue utilizado el software Quatum Gis (Qgis) para ubicar dichas erosiones. El estudio señaló diversas localidades perjudicadas por los trazos erosivos de aproximadamente a unos tres metros de la carretera. Durante la investigación se identificaron once procesos erosivos de suma importancia y de carácter linear, todos con menos de 20 metros de distancia de la carretera.

Palabras clave: Erosión. Barrancas. Zanjas.

Recebido em: 30/05/2020 Aceito para publicação em: 30/06/2020

Publicado em 21/07/2020

\section{Introdução}

Os problemas relacionados aos processos erosivos no solo são recorrentes em áreas periurbanas, devido ao grau de vulnerabilidade da superfície do terreno e está relacionado com o dinamismo da produção das cidades. Do ponto de vista científico, esse tipo de fenômeno, por vezes, impulsionado pela intervenção humana, pode gerar impactos negativos com proporções elevadas a depender da ação dos agentes modeladores do solo. Nessa perspectiva, muitas cidades, seguem prejudicadas por feições erosivas localizadas em perímetros que apresentam contrastes urbanos e rurais. No processo de averiguações destes eventos nos dias atuais, é fundamental o uso de ferramentas geotecnológicas para identificação dessas anomalias no solo, a julgar que tais instrumentos maximizam o tempo e o trabalho do pesquisador. No entanto, não substituem o trabalho de campo.

Para uma análise mais detalhada da situação apresentada, o mapeamento dessas áreas significou uma importante ferramenta para a compreensão e localização destes fenômenos, haja vista que a velocidade e precisão no processamento de uma vasta quantidade de dados por softwares contribuem de forma significativa para a qualidade dos trabalhos acadêmicos.

Ao perceber traços de feições erosivas na zona periurbana da Cidade de Vitória da Conquista - BA foram utilizadas ferramentas digitais que possibilitassem a identificação desses fenômenos no anel rodoviário que circunda a cidade, visto que as condições históricas de manuseio, bem como o condicionamento do sistema de 
drenagem e escoamento superficial no solo, puderam ter proporcionado o desenvolvimento de erosões em estados avançados.

Portanto, o estudo aqui exposto, teve como objetivo principal, mapear as feições erosivas localizadas às margens do anel rodoviário na Cidade de Vitória da Conquista. De fato, ao fazer o levantamento das áreas afetadas, verificou-se extensos processos de erosões lineares relacionados a problemas no sistema de drenagem e falta de cobertura vegetal. Para melhor compreensão das erosões foram, também, classificados os processos mais significativos de acordo à concepção de Vieira (1998 - 2008) sobre ravinas e voçorocas.

Ao contribuir com estudos a cerca do estado das encostas do anel rodoviário da cidade, esta pesquisa poderá favorecer a divulgação do problema e contribuir cientificamente na busca de serviços mitigadores perante as situações encontradas e para que o presente fenômeno não assuma proporções socioambientais cada vez mais graves. Neste aspecto, este estudo tomou características singulares, visto que até o momento não se localizaram trabalhos que dessem o foco ao mapeamento das principais feições erosivas próximas ao anel rodoviário da cidade.

Para realização do presente estudo utilizou-se de procedimentos que foram cruciais para atingir os objetivos da pesquisa, como a utilização de referenciais bibliográficos, tanto em meios analógicos quanto digitais que contribuíram para compreensão dos conceitos e da problemática detectada. Na sequência foi realizado um levantamento de informações por meios digitais de imagens de satélite, que tornou possível localizar as principais áreas afetadas por erosões em um perímetro de até 50 metros às margens do anel rodoviário, com o intuito de maximizar o êxito no trabalho de campo. Após estes procedimentos, com o rascunho das áreas que demonstravam traços de degradação identificados com os programas citados; em campo, foram avaliados e fotografados os locais de estudo para caracterizar os tipos de erosões que se sucedem no perímetro delimitado.

A etapa de análise consistiu na identificação, captação de imagens e classificação dos tipos e as dimensões das erosões lineares. Haja vista que a profundidade, largura, comprimento e as condições de exposição do solo aos fatores de modelagem do relevo foram cruciais para avaliar cada caso em suas especificidades. Esta investigação teve como principal base referencial, as contribuições dos estudos realizados por Vieira (1998 - 2008) referente a fenômenos similares trabalhados. 
O terceiro passo constituiu-se em fazer um mapeamento das principais ravinas e voçorocas identificadas no percurso anterior. Esse procedimento foi fundamental para o atrelamento das informações colhidas, ao tempo em que serviu de suporte, junto com as imagens/fotos, para vislumbrar e concatenar o texto com o objetivo da pesquisa. Ademais, por meio da formação dessa estrutura foi possível aproximar minimamente a compreensão da realidade do objeto de estudo aos leitores. Sendo assim, após ter colhido os dados necessários, as informações foram processadas no Quantum Gis (QGIS) para elaboração dos mapas.

No quarto passo foi realizada uma breve avaliação dos possíveis impactos relacionados aos tipos de erosões encontradas, tendo como alicerces as discussões de Vieira (1998, 2002, 2008), Guerra (1994, 1997), Carvalho e Diniz (2007), Nakajima (2015), Silveira e Mendonça (2009), Ramos e Coelho (2011), (Corrêa, 1986), Sánchez (2013) entre outros.

\section{Apresentação da área de estudo}

Vitória da Conquista é a terceira maior cidade do Estado da Bahia (Mapa 1), com população no último Censo de 2010 em 306.866 mil habitantes, apresenta uma densidade demográfica de 91,41 hab/ $\mathrm{km}^{2}$ (IBGE, 2010). A sua temperatura média anual fica entre $20^{\circ} \mathrm{C}$ e $24^{\circ} \mathrm{C}$, no verão as temperaturas são amenas entorno de $23^{\circ} \mathrm{C}$ e no outono concentra-se em média de $21^{\circ} \mathrm{C}$. O clima do município perpassa pela faixa transacional entre clima úmido e subúmido com características de semiárido, (CABRAL, VEIGA E MATTA, 2015). Em determinados locais sua altitude pode chegar até 1103 metros, como é caso da Serra do Periperi.

Com a velocidade no processo de expansão urbana, a cidade vem sofrendo fortes impactos socioambientais relacionados às consequências de mau uso e ocupação do solo, potencializados por eventos pluviométricos intensos com média de precipitação anual de 750,06mm (MAIA; PINTO; LIMA, 2017). Ainda, em estudo realizados por Barbosa et al. (2017), nos anos de 2012 a 2016 houve concentrações de chuvas intensas nos meses de janeiro, fevereiro, novembro e dezembro, culminando com enxurradas e alagamentos. Este fato relaciona-se com a falta de infraestrutura adequada para suportar eventos como os citados. Neste processo, ao serem direcionadas às margens da malha urbana, as enxurradas acabam provocando incisões no solo ao transportar sedimentos 
das áreas mais desprotegias que, com o passar do tempo, podem evoluir para degradações irreversíveis.

Mapa 1 - Localização do município e da área urbana da Cidade de Vitória da Conquista - BA, 2020.

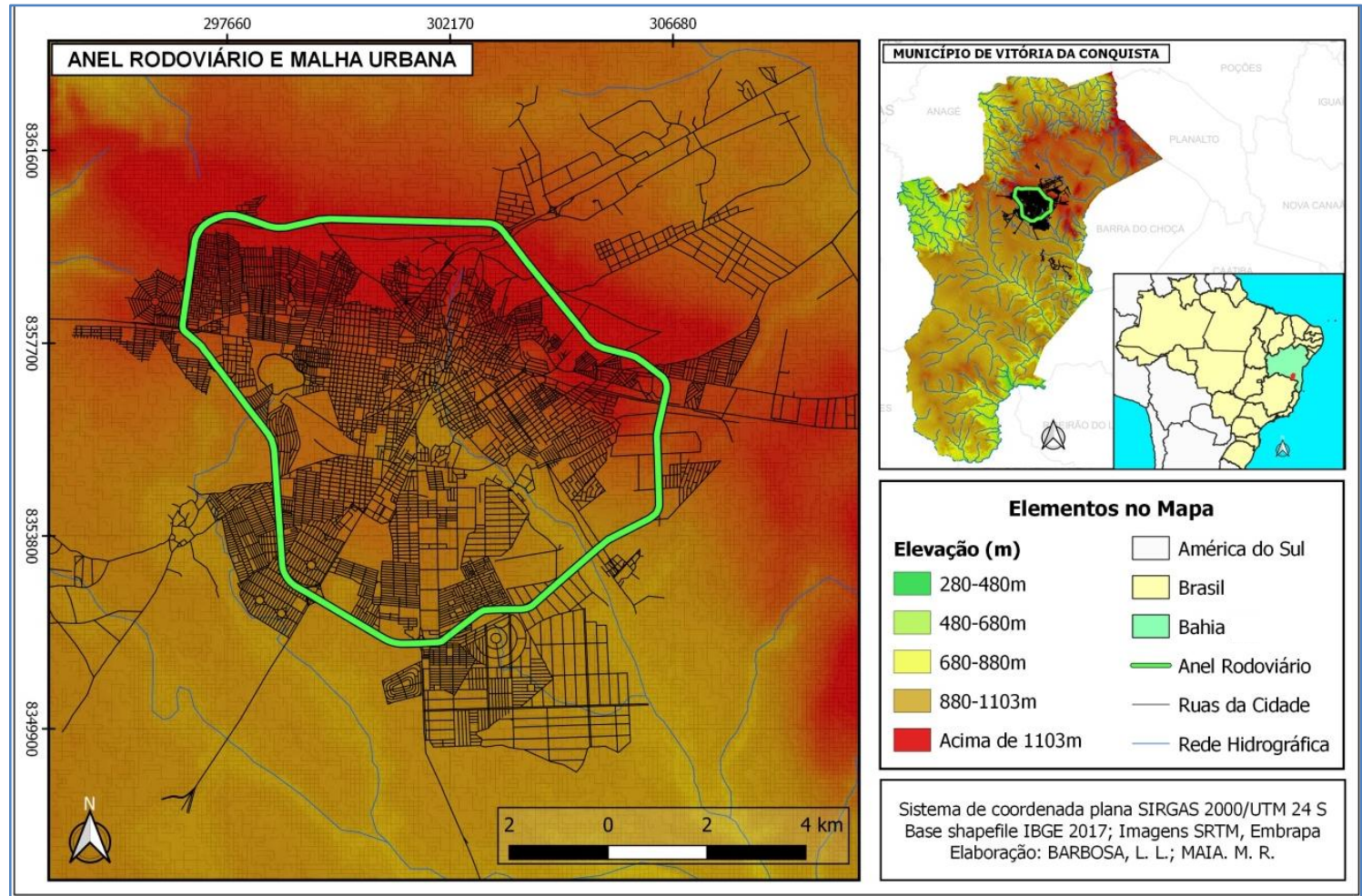

Fonte: IBGE; Embrapa, (2005). Elaboração: BARBOSA, L. L.; MAIA, M. R. (2020)

$\mathrm{O}$ anel rodoviário de Vitória da Conquista com aproximadamente $30 \mathrm{~km}$ de extensão, levando em consideração apenas o perímetro circunferencial foi construído com o intuito de transferir o fluxo de veículos de pequeno e grande porte que trafegavam pelo interior da cidade para as margens da malha urbana, visto que a cidade é vinculada às BR-116, BR-415, BA-262 e BA-265, tais condições provocavam muitos acidentes relacionados aos automóveis que passavam pela cidade.

\section{Processos erosivos: voçorocas e ravinas}

Os processos erosivos no solo são condições naturais relacionadas às interações de um conjunto de fatores que o modelam. Neste contexto, a sociedade pode atuar de forma positiva: quando retarda a evolução de uma erosão com técnicas adequadas, ou negativa: quando provoca ou acelera feições erosivas. Em vista disso, a retirada da cobertura vegetal, o uso e manejo do solo constituem ações pioneiras para a iniciação de 
uma determinada erosão, pois à medida que o solo é exposto haverá com maior facilidade, o transporte de materiais por enxurradas, aguaceiros e chuvas.

Para Filizola et al. (2011, p. 01) "Os principais processos erosivos lineares (ravinas e voçorocas) estão, geralmente associados aos solos arenosos e às cabeceiras dos cursos d'água de primeira ordem". Além das intervenções humanas, os tipos de solos e as condições de relevo influenciam na velocidade do processo de degradação. Contudo é importante destacar que há uma ordem de grandeza para a caracterização da erosão linear, geralmente constituídas por três dimensões diferentes, sulcos, ravinas e voçorocas, na qual, uma dá continuidade à outra. Em suma, a depender do autor ou local de estudo haverá distintas definições e mensurações relacionadas a esse tipo de erosão (GUERRA, 1997; VIEIRA, 1998).

Carvalho e Diniz (2007) consideram os sulcos como a primeira ordem da degradação que consiste em cortes de pouca profundidade no solo; as ravinas seriam o aprofundamento dos sulcos e pode chegar a metros de profundidade e, por fim, a voçoroca, última fase da erosão, teria participação ativa da água subterrânea.

Vieira (2008) considera os sulcos como fissuras de até $50 \mathrm{~cm}$ aprofundadas pela força da água de maneira progressiva e submissa à gravidade; as ravinas são a evolução dos sulcos com profundidade entre $0,50 \mathrm{~m}$ e $1,5 \mathrm{~m}$, apresentando um crescimento tanto progressivo quanto regressivo; já as voçorocas apresentam tamanho maior que 1,5 m com largura superior a $3 \mathrm{~m}$, além disso, está associada à queda de blocos das encostas.

Guerra (1994) apresenta a diferença entre ravinas e voçorocas com base no glossário de ciências do solo dos Estados Unidos de 1987, o qual afirma que para a erosão ser considerada uma voçoroca, ela precisaria possuir mais de $0,50 \mathrm{~m}$ de profundidade e largura, podendo chegar até $30 \mathrm{~m}$ de comprimento, abaixo desse valor seria uma ravina.

Carvalho e Diniz (2007) consideram voçoroca uma erosão que não é formada apenas pela ação de agentes externos, mas também teria a contribuição da água no subsolo. Há, também, quem considera as voçorocas um processo erosivo que teve a capacidade de atingir o lençol freático (NAKAJIMA, 2015). Vieira (2008) estabelece parâmetros qualitativos e quantitativos, não citando a ideia do alcance da erosão ao lençol freático. Neste sentido, Vieira (1998, p. 26) ainda diz que “A diferença básica de uma ravina e uma voçoroca está na forma da calha por onde escoa a água da chuva. $\mathrm{Na}$ ravina, essa calha tem a forma em V [...] e nas voçorocas essa calha tem forma em U". 
Guerra (1994) mostra dimensões pouco exigentes que prioriza apenas aspectos quantitativos. Nesse seguimento, ao citarem Fullen e Catt (2004), Jorge e Guerra dizem que,

Eles procuram diferenciar os dois processos, afirmando que, enquanto as ravinas tendem a fazer incisão, principalmente no horizonte $\mathrm{A}$, as voçorocas atingem facilmente os horizontes $\mathrm{B}$ e $\mathrm{C}$, podendo, por vezes, chegar até a rocha matriz, dependendo da força do processo erosivo. (FULLEN E CATT 2004, Apud JORGE E GUERRA, 2014, p. 13).

Essa última citação poderia apresentar uma conceituação mais satisfatória para a temática, haja vista que cada região do globo apresenta diferentes profundidades dos solos em relação à rocha matriz, o que poderia gerar um conceito globalmente aplicável. Todavia, ao não considerar quesitos quantitativos para mensurar a largura e o comprimento da erosão, seria possível afirmar que qualquer perfuração no solo que atingisse o horizonte B e C poderia ser considerada uma voçoroca. É importante salientar que este questionamento serviu apenas para demonstrar o quão delicado é a compreensão desses fenômenos, sendo assim, Guerra (1994) entende que a classificação desse tipo de erosão deveria seguir um padrão específico para cada região, principalmente para as voçorocas oriundas das condições de ravinamento.

$\mathrm{Na}$ atualidade o desenvolvimento de ravinas e voçorocas está ligado, essencialmente à ação antrópica, não só dos espaços rurais, mas também urbanos, por isso, o planejamento ineficaz de construções que ignoram essas problemáticas deixam o solo propenso a esse tipo de fenômeno (VIEIRA, 2002).

Assim, são nas intermediações entre o urbano e o rural, que as relações socioambientais se entrelaçam de forma singular, no sentido de, ao mesmo passo que os investimentos em infraestrutura são reduzidos nessas áreas, à dependência desses espaços no processo de movimentação do capital especulativo se tornam estratégicas.

Nesse sentido, Corrêa destaca que

O preço da terra agrícola periurbana é influenciado pela expectativa da demanda para fins de urbanização. Neste sentido pode ser conveniente aos proprietários de terra não fazer ali nenhum investimento e utilizar a terra extensivamente ou mesmo deixá-la esterilizada, em "pousio social", à espera da urbanização (CORRÊA, 1986, p. 72). 
Dessa forma, são nas intermediações periurbanas que os processos erosivos podem desencadear proporções significativas na medida em que o escoamento superficial de águas é direcionado às margens da malha urbana e ali encontrarem terrenos propensos à erosão. As águas das chuvas e, muitas vezes de esgotos, devido à impermeabilidade dos espaços pavimentados, ganham velocidade e volume considerando o nível de declividade no percurso que, ao se chocar com áreas desprotegidas, transportam sedimentos gerando incisões no solo desprovido de resistência.

As consequências do processo de erosão acelerada são uma inquietação mundial, sobretudo nos países em desenvolvimento (GUERRA, 1994). Este fato preocupa, visto que tais processos empobrecem a capacidade de produção do solo nos ambientes rurais, geram despesas excessivas, além de afetar a vida de moradores com residências próximas a áreas degradas (ZONTA, 2012). Não muito distante, o aparecimento de erosões no meio urbano e periurbano também apresentam uma série de problemas, como intensificação de proliferação de doenças, de acidentes e deslizamentos de encostas (PEDRON, 2004).

O processo de mapeamento para os estudos de áreas afetadas por erosões tem sua relevância pautada na aproximação da realidade espacial para representação analógica ou digital, e assim, viabilizar ao pesquisador/leitor a compreensão do real. Neste ponto, Ramos e Coelho (2011, p. 6174) consideram que “[...] a cartografia apoiada na utilização e na confecção de mapas pode gerar resultados que possibilitam acompanhar temporalmente as transformações ocorridas na área de estudo e facilitam a visualização dos resultados.”. Por meio do mapeamento dos locais de estudo, o pesquisador consegue ter dimensões de problemas que não poderiam ser visualizados diretamente na localidade onde se encontra o objeto a ser pesquisado. Portanto, foi necessário representar os processos de erosão por meios digitalizados para posteriormente serem elaborados estudos diretamente relacionados às erosões em si.

\section{Ravinas e voçorocas nas margens do anel rodoviário em Vitória da Conquista}

A construção do Anel Rodoviário em Vitória da Conquista é considerada complexa desde o planejamento a conclusão. Obras como essa podem gerar consequências graves ao meio ambiente quando não são executadas às luzes das 
exigências mínimas previstas nas leis que regimentam o processo de preservação do meio ambiente. Neste sentido, a Constituição Federal de 1988 no artigo 225, § $1^{\circ}$, inc. IV incube ao poder público o dever de garantir o meio ambiente ecologicamente preservado para presentes e futuras gerações: "exigir, na forma da lei, para instalação de obra ou atividade potencialmente causadora de significativa degradação do meio ambiente, estudo prévio de impacto ambiental, a que se dará publicidade”. Segundo o Plano Diretor de Desenvolvimento Urbano (PDDU) de Vitória da Conquista, no Produto 7, Tomo II, Volume IV,

A conclusão do anel rodoviário em 2002 não foi acompanhada de estudos sobre o uso e ocupação do solo no entorno e, ao invés de conter as expansões num perímetro urbano mais compacto, planejado e regulamentado, acabou contribuindo para novas expansões. Um problema viário pouco trabalhado no PDDU em vigor, sem diretrizes claras para a existência de muitos terrenos desocupados fora do anel [...]. (PDDU, 2018, p. 24).

A preocupação em preservar o meio ambiente no que diz respeito à construção civil não pode ser assegurada apenas no período de execução da obra, mas, sobretudo em seu processo de manutenção. Trazendo para realidade aqui estudada, mesmo que todas as normas dentro da lei foram cumpridas durante a construção do anel rodoviário, a falta de manutenção adequada pôde ter dado espaço ao aparecimento de ravinas e voçorocas no entorno do anel. Ainda, ao observar a opinião contida no PDDU sobre a falta de planejamento ao uso e ocupação do solo, somadas a fala de Corrêa (1986) a respeito dos proprietários de terra que buscam a valorização dos terrenos agrícolas próximos às redes urbanas, com o restante das discussões, é evidente que os casos das erosões próximas ao anel rodoviário da cidade de Vitória da Conquista são frutos dessas problemáticas.

Com base nas informações apresentadas e nas classificações elaboradas para caracterização das ravinas e voçorocas nos trabalhos de Vieira (1998 - 2008), o estudo aqui presente aproximou-se de seus métodos para designar a proximidade dos processos de erosão encontrados às margens do anel rodoviário da cidade de Vitória da Conquista, e assim, adotá-los e prosseguir neste estudo.

Durante a pesquisa foram identificados onze processos erosivos significativos de caráter linear, todos com menos de vinte metros da pista, alguns pontos chegando até três metros de distância. O Mapa 2 exibe a localização de cada erosão entorno ao anel 
rodoviário. Como os sulcos são incisões pequenas no solo, não foi priorizada a demarcação das áreas que apresentassem esse processo, o que não deixa de ser preocupantes, pois são a partir deles que erosões maiores evoluem.

Mapa 2 - Localização de ravinas e voçorocas às margens do anel rodoviário da cidade de Vitória da Conquista - BA, 2020.

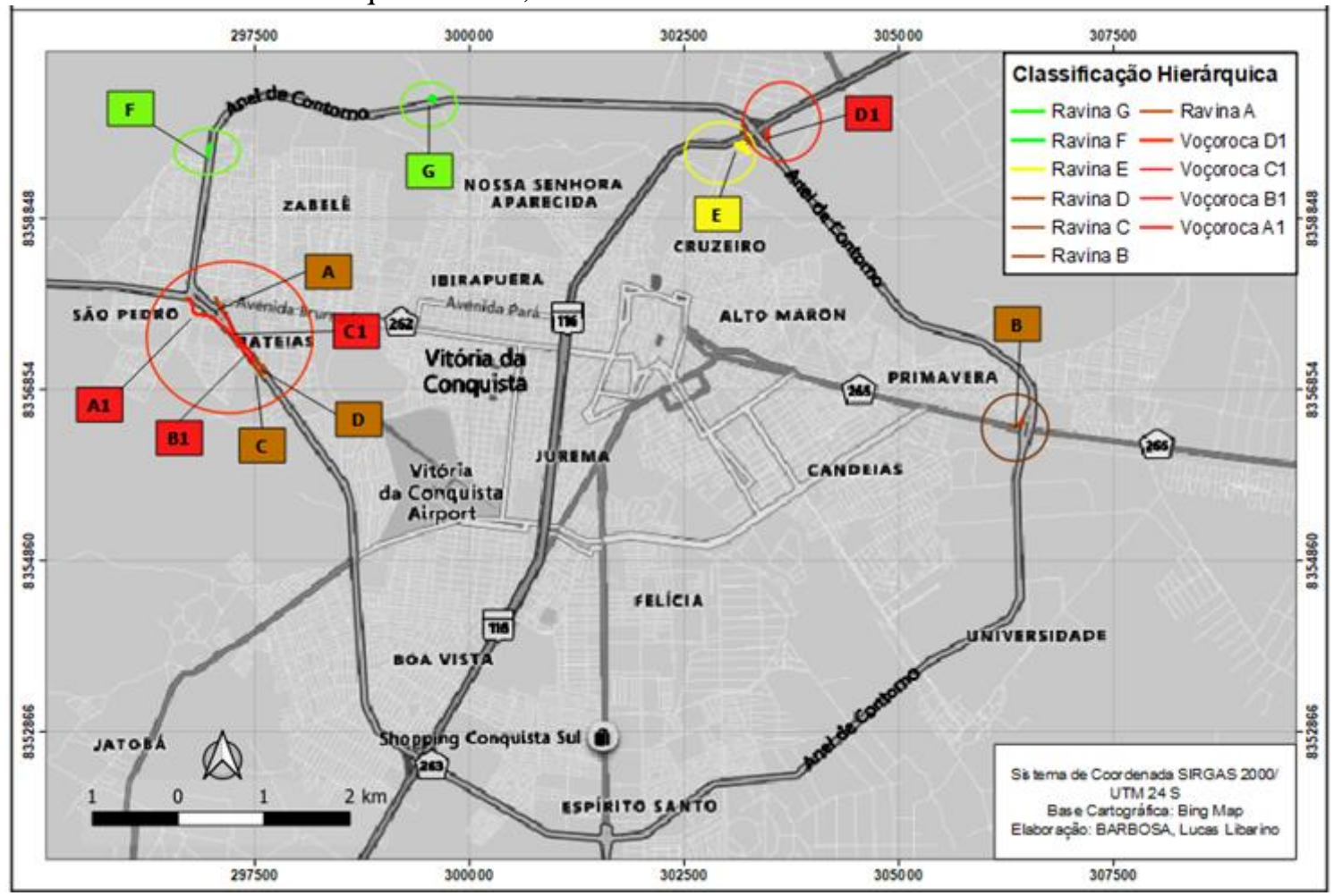

Fonte: Bing Map, 2020. Elaboração: BARBOSA, Lucas Libarino.

As feições erosivas aqui presentes foram hierarquizadas para a melhor compreensão e dimensão de cada caso. Assim sendo, a cor verde representa ravinas que se derivaram de sulcos, porém, ainda em seu processo inicial; a de cor amarela representa uma ravina bem evoluída; as em cores marrons são ravinas que estão próximas das dimensões de uma voçoroca, faltando pouco para se tornarem uma; já as em vermelho são processos erosivos avançados e podem ser caracterizados como voçorocas.

O Mapa 2, também, destaca que a maior aglomeração de erosões acontece no perímetro oeste do anel, totalizando oito processos, os quais estão inclusos as feições mais graves. Assim, é importante relatar que as erosões A1, B1 e C, são erosões interligadas, bem como as $\mathrm{A}, \mathrm{C} 1$ e $\mathrm{D}$, o que as diferenciam são as dimensões em profundidade e largura. Dessa forma, levando em consideração o conceito de erosão 
linear em Vieira (1998 - 2008), durante o percurso de cada uma, no ponto em que a profundidade não ultrapassou $1,5 \mathrm{~m}$ ou a largura em $3 \mathrm{~m}$, as erosões deixaram de ser consideradas voçorocas e passaram a ser ravinas e vice-versa.

Devido ao número de erosões aqui apresentado, buscou-se fazer considerações mais aprofundadas a respeito das voçorocas, pois são feições em estados avançados que precisam de uma atenção maior e mais urgente (Painel 1 e 2).

Painel 1 - Dimensões das voçorocas A1 e B1 por imagem aérea, margens do Anel Rodoviário Vitória da Conquista - BA, 2020
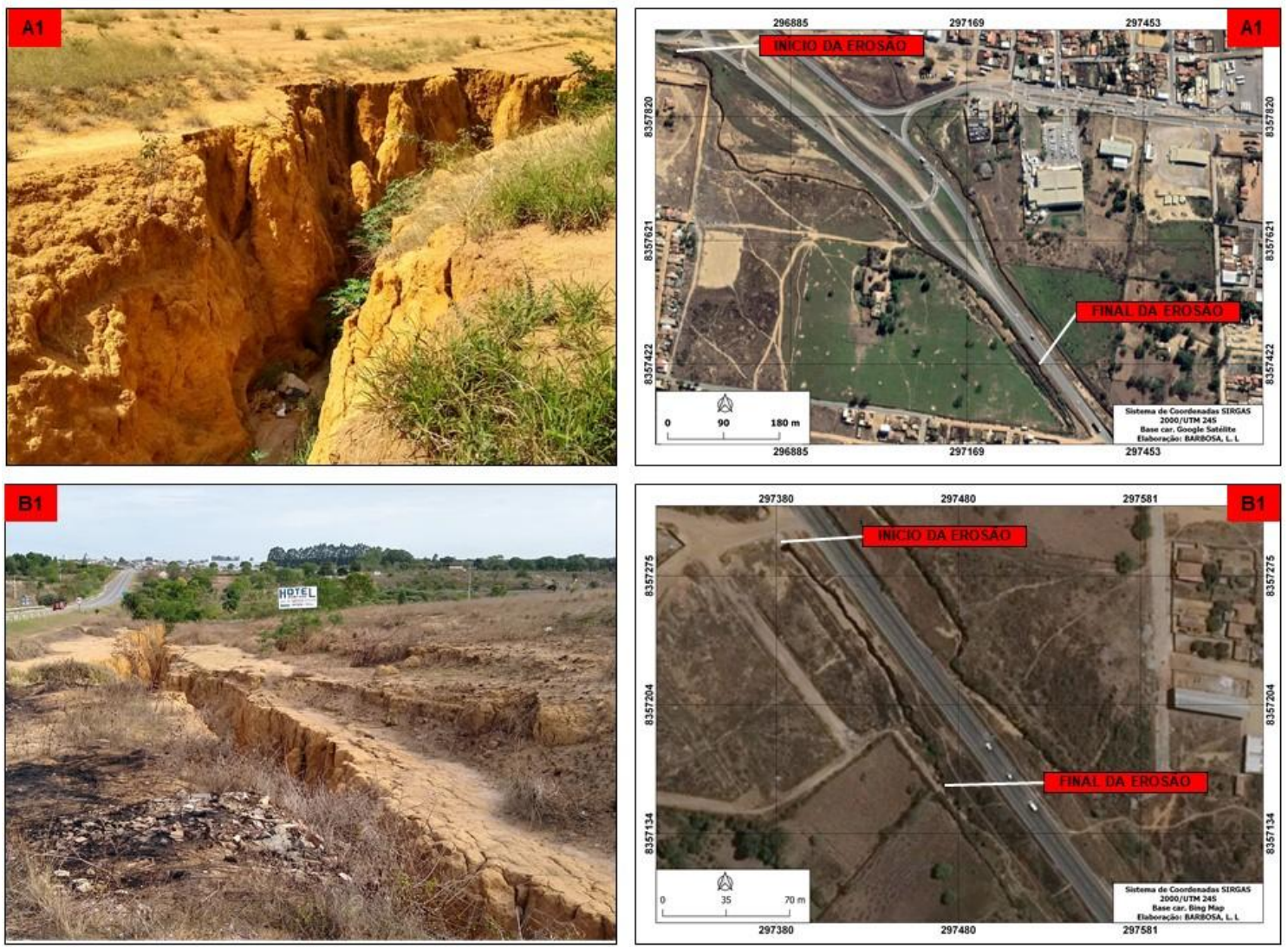

Fonte: Org. BARBOSA, Lucas Libarino. Foto, (Janeiro de 2020).

A voçoroca A1 apresentou 985 metros de extensão, nos primeiros metros da erosão a sua largura alcança 7,50 metros, essa dimensão percorre grande parte do percurso variando para mais ou menos. Sua profundidade oscila entorno de 9 metros, de acordo à composição do solo e terraplanagem. De formato linear, seu ponto inicial está localizado a $14^{\circ} 50^{\prime} 43^{\prime}$ 'S $/ 40^{\circ} 53^{\prime} 22^{\prime} \mathrm{W}$, na maior parte de seu percurso exibiu feições inconstantes com características de desbarrancamento das paredes e falta de cobertura vegetal apropriada. 
A voçoroca B1 demonstrou um comprimento aproximado em 138 metros, com larguras que vão de 8 a 4 metros na maior parte de sua extensão, tem sua profundidade nos intermédios da cabeceira em 11 metros, e oscilações para menos até o final. Com o formato linear, essa erosão apontou queda de blocos das encostas e falta de cobertura vegetal adequada, tendo seu ponto inicial localizado a $14^{\circ} 51^{\prime} 04^{\prime \prime} \mathrm{S} / 40^{\circ} 52^{\prime} 59^{\prime \prime} \mathrm{W}$.

Painel 2 - Dimensões das voçorocas C1 e D1 por imagem aérea, Anel Rodoviário, Vitória da Conquista - BA, 2020
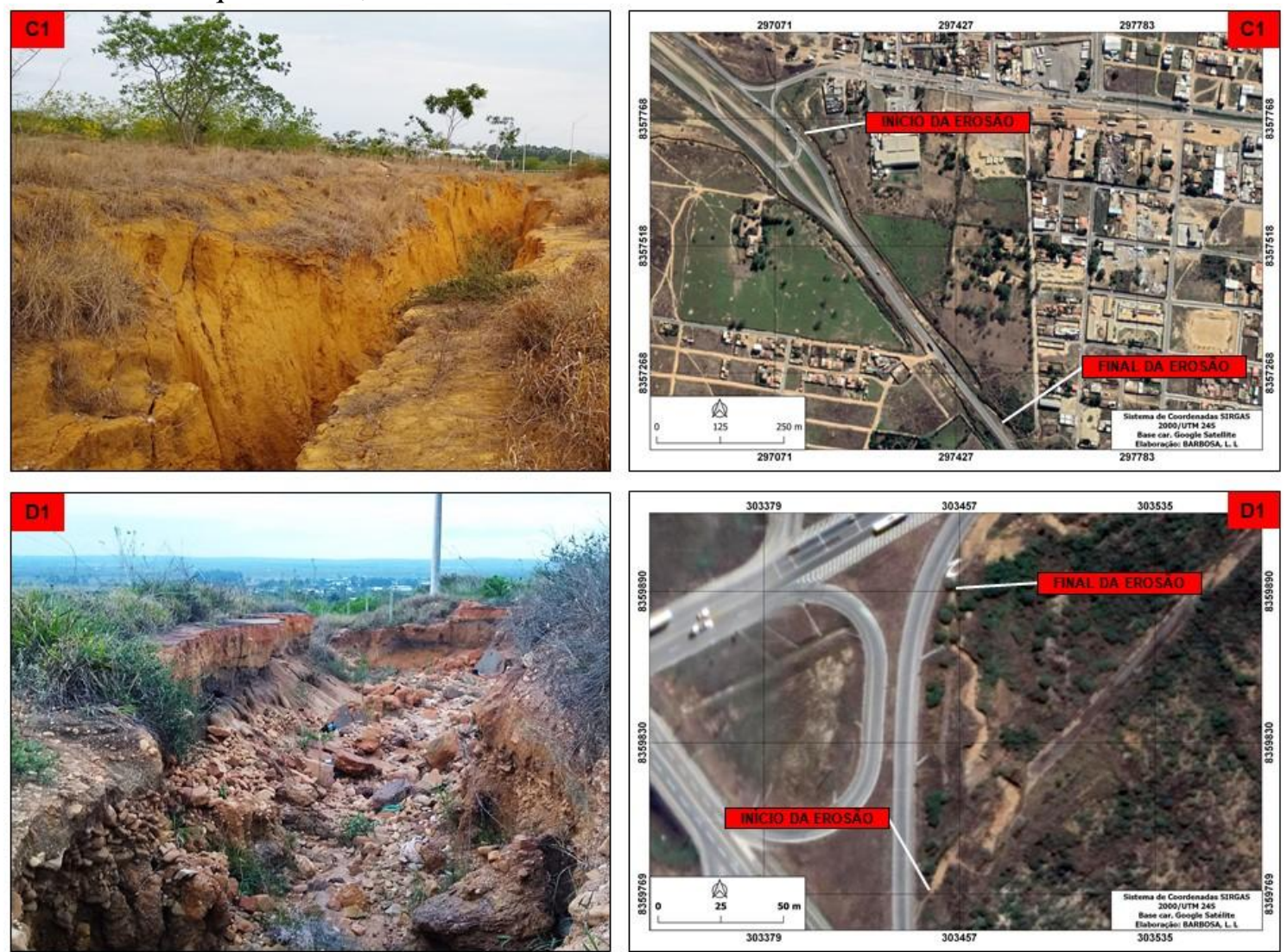

Fonte: Org. BARBOSA, Lucas Libarino. Foto (Janeiro de 2020).

A erosão $\mathrm{C} 1$ segue de forma semelhante ao mesmo delineado da A1, mas do lado oposto à via automobilística. Essa voçoroca tem 640 metros de comprimento, expôs profundidade de 8,5 metros nas intermediações de sua cabeceira, com alternâncias deste valor durante a sua extensão. Também apresentou feições de desbarrancamento das paredes e falta de cobertura vegetal apropriada. Sua largura varia de 4 a 8 metros em todo seu trajeto, com distância relativa à pista entre 3 a 13 metros e está localizada a $14^{\circ} 50^{\prime} 40^{\prime \prime} \mathrm{S} / 40^{\circ} 53^{\prime} 07^{\prime \prime} \mathrm{W}$.

$\mathrm{Na}$ voçoroca D1, localizada ao nordeste do anel a $14^{\circ} 49^{\prime} 45^{\prime \prime} \mathrm{S} / 40^{\circ} 49^{\prime} 35^{\prime \prime} \mathrm{W}$, apresentou uma formação diferente das outras em relação às características do solo, no 
qual se observa uma área mais pedregosa, profundidade oscilando entorno de 3 metros, com extensão de 123 metros. Seu ponto mais próximo à pista está a 8,5 metros e o mais longo a 16,7 metros. Assim como as outras, não se identificou cobertura vegetal adequada para diminuição dos impactos pluviais e em grande parte de sua extensão foi observado perfis com presença de queda de blocos das encostas.

Painel 3 - Imagens da voçoroca A1 e C1, Anel Rodoviário, Vitória da Conquista - BA, 2020.

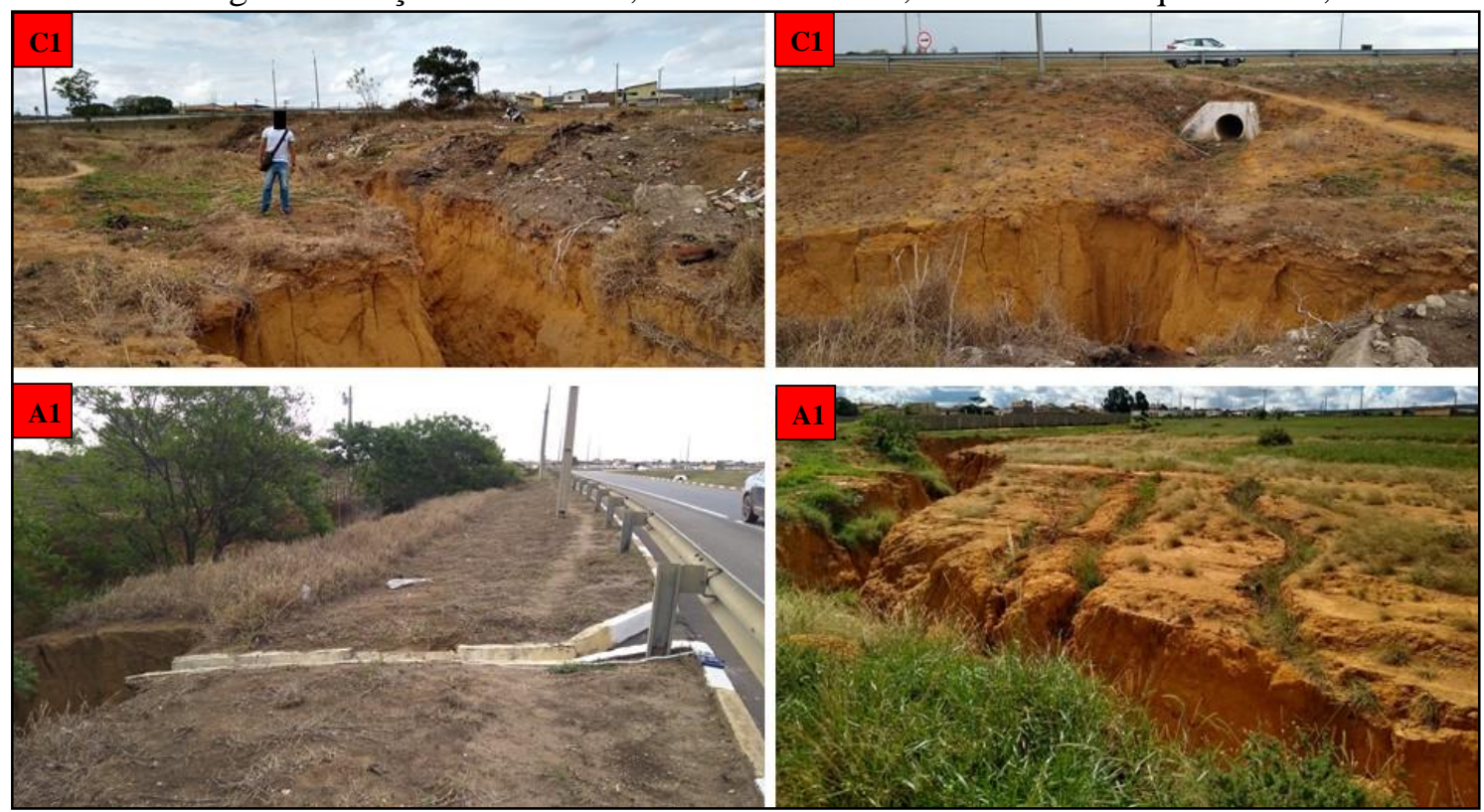

Fonte: Pesquisa de campo, foto BARBOSA, Lucas Libarino (Janeiro de 2020).

O sistema de drenagem é essencial para o funcionamento das rodovias, uma vez que, sua função principal seria obliterar a ação erosiva da água sobre a pista de transição automobilística, porém, sua implantação inadequada pode acarretar problemas relacionados à forma como o processo de drenagem atuará nas intermediações das rodovias ou nelas mesmas.

Em estudo feito por Silveira e Mendonça (2009, p. 238), ao analisarem uma voçoroca às margens de uma rodovia no Município de Paraíso do Tocantins - TO observou-se que uma das principais causas que pôde ter acarretado o processo erosivo no local foi "[...] à canalização das águas pluviais em função da ausência de drenagem adequado no início da construção da rodovia, o que geraria o entalhamento de erosões em sulcos e ravinas que posteriormente evoluiria para o estágio atual de voçorocamento".

Com base nessas informações, durante a pesquisa sobre o anel rodoviário em Vitória da Conquista, notou-se em vários pontos a falta de bacias de amortecimento 
(dissipadoras de energia), a qual teria a finalidade de atenuar o impacto das águas que ganham velocidade sobre as descidas d'água construídas sobre os taludes, drenadas da pista para o solo. Da mesma forma, foram identificados bueiros direcionados as erosões sem sinais de sistemas de amortecimento de fluídos (Painel 3). Portanto, pode-se inferir que tais condições somadas a outros fatores como falta de cobertura vegetal adequada, a declividade do terreno e o tipo de solo, puderam ser determinantes para a formação das voçorocas. Assim, os sulcos e ravinas quando não obliterados no início, podem evoluir para voçorocas devido o impacto das águas nas paredes e bases de tais feições (GUERRA, 1997) (Painel 4).

Painel 4 - Comparação das feições erosivas A1 e C1, Anel Rodoviário, Vitória da Conquista BA, de 2003 para 2018

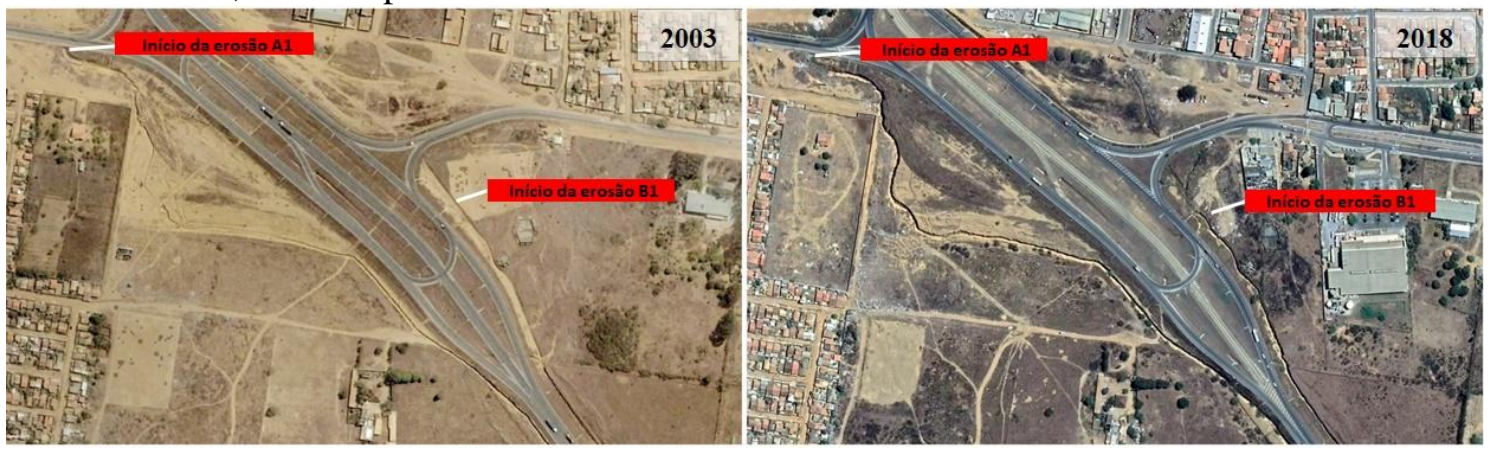

Fonte: Google Earth Pro. Org. BARBOSA, Lucas Libarino. (2020)

É possível identificar no Painel 4 a evolução das voçorocas A1 e C1 e como ganharam proporção em um período de 15 anos. Ainda, é possível observar a falta de cobertura vegetal apropriada para a contenção dos impactos pluviais nos dois períodos. A modificação brusca do espaço natural acarreta em desordens nos sistemas ambientais estabelecidos antes do contato humano, porém ao depender dos recursos naturais para a sobrevivência, a sociedade, ao modificar o espaço, deve estar atenta aos impactos derivados dessas modificações.

$\mathrm{Na}$ atualidade, prescreve-se que para a construção de determinadas obras no meio ambiente, devem ser realizados estudos que preveem e mitiguem os impactos negativos gerados pela manipulação antrópica no ambiente; aqui a Avaliação de Impacto Ambiental (AIA) e o Relatório de Impacto Ambiental (RIMA) e outros, são documentos fundamentais para o licenciamento de empreendimentos que condicionam mudanças relevantes na natureza. O primeiro é responsável por estudar os possíveis impactos ambientais na instalação de obras futuras; o segundo é um relatório acessível 
ao público, resumido do Estudo de Impacto Ambiental (EIA), o qual é um documento com maior teor técnico (SÁNCHEZ, 2013). Neste sentido, os responsáveis por atividades que se dispôs da necessidade de tais estudos, são circunspectos, não só do processo de construção em si, mas, também posterior a ela.

Na Resolução no 001 de 1986 do CONAMA no Artigo 6º, inc. IV, aponta a "Elaboração do programa de acompanhamento e monitoramento dos impactos positivos e negativos, indicando os fatores e parâmetros a serem considerados", como um dos requisitos mínimos para o EIA. Sobre isso, segundo Sánchez (2013) esse acompanhamento é função do empreendedor e do órgão governamental. Assim, cabe ao empreendedor o processo de monitoramento, implementação, documentação e análise, além da realização de auditorias. Ao agente público ficaria com a responsabilidade pela análise e fiscalização em todo o percurso.

Tais considerações abarcam minimamente a complexidade e importância dos estudos de impactos ambientais na natureza. Isso implica, também, no questionamento sobre se essas medidas foram adotadas no processo de construção do anel rodoviário da cidade de Vitória da Conquista, tendo em vista todos os problemas relacionados às erosões encontradas nas intermediações do anel apresentadas neste estudo. $\mathrm{O}$ fato é que essas erosões, além de trazerem prejuízo ao meio ambiente e a questões econômicas, geram desconforto e risco a população que utiliza a via para trafegar. Ademais, todas essas condições são maximizadas em áreas urbanas, ao observar que com o intenso fluxo de veículos e pessoas diante as incisões próximas à pista, aumentam ainda mais o risco de acidentes provenientes desses fenômenos.

\section{Considerações finais}

Os impactos gerados no meio ambiente, atrelados à interferência humana, são inevitáveis, visto que a qualidade de vida social está direta e indiretamente interligada a utilização dos recursos naturais, tidos como elementos básicos para a sobrevivência. Assim, resta, portanto, a tomada de ações que minimizem os problemas desenvolvidos durante o processo de apropriação desses recursos. Contudo, negligenciar as medidas de preservação ambiental é colocar a própria natureza contra a sociedade, pois tomando como exemplo o caso apresentado neste trabalho, a falta de atenção as recomendações de preservação do solo próximo ao anel rodoviário, não só coloca em perigo o terreno 
em si, mas também a população e a própria pista que, com o tempo, pode ser atingida pelas voçorocas.

Assim, o trabalho aqui exposto, evidenciou intensos processos erosivos às margens do anel rodoviário da cidade de Vitória da Conquista na Bahia. As ravinas e voçorocas averiguadas demonstram feições em estado avançado, ao observar que suas medidas ultrapassam consideravelmente as especificações apresentas por Vieira (1998 2008) e Guerra (1994), além de estarem localizadas próximas à pista do anel rodoviário. Também foi possível entender que tais condições não são estáticas, mas tendem a evoluir perante interferências naturais e não naturais durante o tempo.

Portanto, a importância do mapeamento dos processos erosivos próximos ao anel, relacionou-se a capacidade de registrar a localização e proporcionar a visualização das ravinas e, principalmente das voçorocas em dimensões acessíveis ao leitor e pesquisador. Neste contexto, a compreensão a fundo desse fenômeno perpassa uma série de etapas, assim, o mapeamento pode ser considerado uma das fases pioneiras e essenciais, visto que sua função antecede todas as outras práticas que abarcam as erosões, no sentido em que as erosões já localizadas, maximizariam o tempo para a tomada de decisões caso seja requerida outras etapas de estudo ou de obliteração das erosões mapeadas.

Assim, ao fazer pequenas observações sobre as ravinas e voçorocas e, levando em consideração o curto espaço de tempo e a temática propostas deste trabalho, este estudo não se esgota aqui, mas há a necessidade de levá-lo adiante para compreender com maior precisão os processos erosivos discutidos aqui, e assim, serem tomadas as decisões pertinentes para o bom funcionamento dos ambientes que foram afetados.

\section{Referências}

BARBOSA, Lucas Libarino et al. Vulnerabilidades de impactos hidrometeóricos na cidade de Vitória da Conquista - BA: estudo das precipitações entre os anos de 2012 a 2016. In:

Educação ambiental: biomas, paisagens e o saber ambiental / Giovanni Seabra (Org). Ituiutaba: Barlavento, 2017. Disponível em: <https://bit.ly/3fs6McW>. Acessado em: 20 de mai. de 2020.

BRASIL. [Constituição (1988)]. Constituição da República Federativa do Brasil de 1988. Brasília, DF: Presidência da República. Disponível em: http://www.planalto.gov.br/ccivil_03/ constituicao/constituicao.htm Acesso em: 20 de mai. de 2020. 
BRASIL. Resolução CONAMA n. 001/1986. Dispõe sobre critérios básicos e diretrizes gerais para a avaliação de impacto ambiental. Disponível em: <http://www.mma.gov.br/port /conama/legiabre.cfm?codlegi=23>. Acessado em: 20 de mai. de 2020.

CABRAL, Leandro de Oliveira; VEIGA, Artur José Pires; MATTA, Jana Maruska Buuda da. Climatologia e saúde: o ensino dos elementos meteorológicos e sua relação com a incidência de doenças respiratórias. Colóquio do Museu Pedagógico, v. 1, 2015. Disponível em http://periodicos.uesb.br/index.php/cmp/ article/ view/5013. Acesso em Acessado em: 11/04/2018.

CARVALHO, José Camapum de; DINIZ, Noris Costa. Cartilha erosão. Brasília: Universidade de Brasília: FINATEC, il. $3^{\circ}$ edição 2007. Disponível em: <

https://www.geotecnia.unb.br/downloads/publicacoes/cartilhas/cartilha_erosao_2007.pdf>.

Acessado em: 26 de mar. de 2019.

CORREAA, R. L. A periferia urbana. GEOSUL: Revista do departamento de Geociências (UFSC), ano I, n. 2, 1986. Disponível em: <https://periodicos.ufsc.br/index.php/geosul/ article/view/12551/11859>. Acesso em: 08 mai. 2020.

FILIZOLA, Heloisa Ferreira et al. Controle dos processos erosivos lineares, ravina e voçorocas, em área de solos arenosos. Jaguariúna: EMBRAPA Meio Ambiente, 2011. Disponível em: <http://www.cnpma.embrapa.br/download/circular_22.pdf> . Acessado em: 26 de mar. de 2019.

GUERRA, Antonio José Teixeira. A erosão de solos no contexto social. Anuário do Instituto de Geociências da Universidade Federal do Rio de Janeiro, Rio de Janeiro, v. 17, p. 14-23, 1994. Disponível em: <https://revistas.ufrj.br/index.php/aigeo/article/view/6147/4744>. Acessado em mai. 2020.

GUERRA, Antonio José Teixeira. Processos erosivos nas encostas. In. GUERRA, Antonio José Teixeira; CUNHA, Sandra Batista da. (org.) Geomorfologia: uma atualização de base e conceitos. Rio de Janeiro: Bertrand Brasil, 1994.

GUERRA, Antonio José Teixeira. Ravinas: processo de formação e desenvolvimento. Revista Anuário do Instituto de Geociências - Volume 20 - pp. 9-26 - 1997. Disponível em: $<$ https://revistas.ufrj.br/index.php/aigeo/article/viewFile/6180/4777>. Acessado em: 26 de mar. de 2019.

JORGE, Maria do Carmo Oliveira; GUERRA, Antonio José Teixeira. Erosão dos solos e movimentos de massa - recuperação de áreas degradadas com técnicas de bioengenharia e prevenção de acidentes In. Processos erosivos e recuperação de áreas degradadas / Antonio José Teixeira Guerra, Maria do Carmo Oliveira Jorge, organizadores. $1^{\mathrm{a}}$ ed. $1^{\mathrm{a}}$ reimpressão -São Paulo: Oficina de Textos, 2014.

MAIA, Meirilane Rodrigues; PINTO, Josefa Eliane Santana de Siqueira; LIMA, Espedito Maia. Eventos pluviométricos extremos na Cidade de Vitória da Conquista (BA) entre 1995 e 2015. Revista GeoNordeste, São Cristóvão, Ano XXVIII, n. 2, p. 42-55, Jul./Dez. 2017. Disponível em: https://ri.ufs.br/bitstream/riufs/9152/2/Geonordeste_2_2017. Acessado em: 08 de mai. de 2020.

NAKAJIMA, Karem K. Proposta de técnicas de controle da erosão às margens da PR-317 entre Floresta e Peabirú. Trabalho de Conclusão de Curso (Graduação em Engenharia Civil) Universidade Tecnológica Federal do Paraná, Campo Mourão, 2015. Disponível em: http://repositorio.roca.utfpr.edu.br/jspui/bitstream/1/6714/1/CM_COECI_2015_2_22.pdf.

Acessado em: 26 de mar. de 2019. 
PEDRON, Fabrício de Araújo et al.. Solos urbanos. Ciência Rural, Santa Maria, v.34, n.5, p.1647-1653, set-out, 2004. Disponível em: https://www.scielo.br/pdf/cr/v34n5/a53v34n5. Acessado em: 09 de mai. 2020

RAMOS, André Luís Demuner; COELHO, André Luiz Nascentes. Uso de Geotecnologias para Análise e Compreensão das Dinâmicas das Áreas de Proteção Permanente (APPs) do Canal Principal da Bacia Hidrográfica do Rio Doce - Porção de Linhares / Espírito Santo. Anais XV Simpósio Brasileiro de Sensoriamento Remoto - SBSR, Curitiba, PR, Brasil, 30 de abril a 05 de maio de 2011, INPE p.6169. Disponível em: <marte.sid.inpe.br/col/dpi.inpe.br/marte /2011/07.13.16.46/doc/p0384>. Acessado em: 08 de mai. de 2020.

SÁNCHEZ, Luis Enrique. Avaliação de impacto ambiental: conceitos e métodos. -- 2. ed. -São Paulo : Oficina de Textos, 2013.

SILVEIRA, Leonardo Ramos da; MENDONÇA, Rose Mary Gondim. Análise, monitoramento e caracterização da voçoroca ribeirão da cachorra em paraíso do Tocantins - TO. Engenharia Ambiental - Espírito Santo do Pinhal, v. 6, n. 2, p. 231-250, mai/ago 2009. Disponível em: <ferramentas.unipinhal.edu.br>. Acessado em: 26 de mar. de 2019.

VIEIRA, Antonio Fábio Sabbá Guimarães. Definições, classificações e formas de voçorocas. Anais do IV SINAGEO, São Luís- MA, p. 105-106, 2002. Disponível em: < http://lsie.unb.br/ugb/sinageos/detalhe/7>. Acessado em: 26 de mar. de 2019.

VIEIRA, Antonio Fábio Sabbá Guimarães. Desenvolvimento e distribuição de voçorocas em Manaus (AM): principais fatores controladores e impactos urbanos-ambientais. (Tese de doutorado em Geografia): Departamento de Geografia. UFSC, 2008. Disponível em: < https://repositorio.ufsc.br/handle/123456789/91352>. Acessado em: 26 de mar. de 2019.

VIEIRA, Antonio Fábio Sabbá Guimarães. Erosão por voçorocas em áreas urbanas: o caso de Manaus (AM). Dissertação (Mestrado). Florianopolis: UFSC, 1998. 222p. Disponível em: https://repositorio.ufsc.br/xmlui/handle/123456789/77508>. Acessado em: Acessado em: 26 de mar. de 2019.

VITÓRIA DA CONQUISTA. Contrato no 019-35/2018. Planos Diretores de Desenvolvimento Urbano e Agência Reguladora Municipal. PMVC-PDDU-RT-005-R1, Produto 7, Tomo II, volume IV. Salvador, outubro de 2018. Disponível em: <https://www.pmvc.ba.gov.br/pddu/>. Acessado em: 20 de mai. de 2020.

ZONTA, João Henrique. et al. Práticas de Conservação de Solo e Água. Campina Grande, PB: Embrapa - Algodão. Circular Técnica, 133, Setembro, 2012, p. 24. Disponível em: < https://www.infoteca.cnptia.embrapa.br/infoteca/handle/doc/928493>. Acessado em: 08 de mai. 2020. 